\title{
Panorama do sistema construtivo light wood frame no Brasil
}

\author{
Brazilian light wood frame system overview
}

\section{Nicolle Christine Sotsek Adriana de Paula Lacerda Santos}

\section{Resumo}

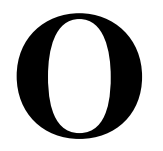

light wood frame (LWF) representa grande inovação para o setor de construção civil no Brasil, devido a suas características de racionalização de material, flexibilidade operacional, agilidade produtiva, custos competitivos e, também, pelos níveis eficientes de limpeza e tempo de montagem. Por esses motivos, esse sistema é considerado uma alternativa construtiva promissora. O objetivo deste estudo é explorar o potencial do sistema no Brasil. Esta pesquisa é um estudo exploratório que utiliza como instrumento de coleta um questionário de avaliação qualitativa aplicado com representantes da construção civil envolvidos com o LWF. O estudo propõe analisar as variáveis críticas que devem ser gerenciadas dentro do setor, investiga as necessidades e os potenciais do sistema construtivo e formula estratégias competitivas para a difusão do LWF no país. Os resultados da pesquisa mostram que a expansão do LWF no Brasil é fortemente dependente dos incentivos governamentais, do aumento da integração dos agentes tanto da cadeia de valor da construção civil como do setor de madeireiro, da necessidade de disseminar mais informações aos usuários finais como forma de combate ao preconceito em relação ao uso da madeira e, por fim, da necessidade de formar profissionais para atuar de forma direta com a construção em madeira.

Palavras-chave: Light wood frame. Cenários prospectivos. Sistemas construtivos inovadores. Construção civil.

\begin{abstract}
Light wood frame (LWF) represents a great innovation for the civil construction sector in Brazil, due to its characteristics of material rationalization, operational flexibility, productive agility, competitive costs and also the efficient levels of cleaning and assembly time. For these reasons, this system is considered a promising constructive alternative. The objective of this study is to explore the potential of the system in Brazil. This research is an exploratory study, which uses as a collection tool a questionnaire of qualitative evaluation, applied with representatives of the civil construction involved with the LWF. The study

proposes to analyze the critical variables that must be managed within the sector; investigates the needs and potentials of the constructive system; formulates competitive strategies for the diffusion of LWF in the country. The research results show that the expansion of LWF in Brazil is heavily dependent on government incentives; the increase in the integration of agents in both the civil construction value chain and the lumber sector; the need to disseminate more information to end users as a way to combat prejudice with the use of wood; and finally the need to train professionals to work directly with wood construction.
\end{abstract}

Nicolle Christine Sotsek Universidade Federal do Paraná Curitiba - PR - Brasil

Adriane de Paula Lacerda

Santos Universidade Federal do Paraná Curitiba - PR - Brasil

Recebido em 25/07/17 Aceito em 22/01/18
Keywords: Light wood frame. Prospective scenarios. Innovative building systems. Brazilian construction. 


\section{Introdução}

O sistema construtivo light wood frame (LWF), por décadas, tem sido uma tecnologia ${ }^{1}$ relevante e popular em países desenvolvidos da Europa, Oceania e América do Norte. Hoje mais de 90\% das novas construções americanas são feitas com alguma versão do sistema (THALLON, 2008). Já no Brasil a realidade é outra. O principal sistema construtivo ainda é a alvenaria de blocos. Segundo Nascimento (2004), culturalmente a grande aplicabilidade deste sistema construtivo está na presunção de que a alvenaria tem maior durabilidade, embora essa vantagem seja questionada por diversos autores.

Percebe-se mesmo assim que, em função de suas características promissoras, o LWF começa a ser explorado também no Brasil, por conta principalmente da necessidade de novos insumos, pela flexibilidade no processo de fabricação, pela alta velocidade de montagem, pela padronização dos processos (THALLON, 2008) e, ainda, devido à preocupação pela busca de sistemas construtivos mais eficientes para contribuir com a sustentabilidade ambiental (MAHAPATRA; GUSTAVSSON; HEMSTRÖM, 2012). Para Wang, Toppinen e Juslin (2014), aumentar o uso da madeira na construção ajudaria a atingir os objetivos de desenvolvimento sustentável de forma mundial. Segundo Mahapatra (2007), a substituição do material de madeira por outros materiais de construção, como concreto e aço, pode reduzir as emissões líquidas de $\mathrm{CO}_{2}$ e o uso de energia primária, visto que, de acordo com Jadid e Badrah (2012), o setor de construção civil é um dos maiores consumidores desses insumos no mundo.

Além dessas vantagens, o Brasil possui enorme disponibilidade de áreas de reflorestamento. As duas espécies mais utilizadas para esse fim, pínus e eucalipto, apresentam elevada taxa de crescimento. A madeira, em sua maioria, tem fácil trabalhabilidade e excelente desempenho térmico e acústico, além de elevada relação resistência-peso (MOLINA; CALIL, 2010), o que faz dela um insumo promissor para o setor da construção civil no país. Segundo Gold e Rubik (2009), a madeira como um recurso renovável pode contribuir para estabelecer padrões de consumo e produções mais sustentáveis.

Entretanto, a difusão de uma nova tecnologia nem sempre é um caminho simples a percorrer. Segundo Mahapatra (2007), a difusão de uma inovação depende dos atores da cadeia de suprimentos (fornecedores, fabricantes, prestadores de serviço) e

1Tecnologia: “[...] um conjunto de conhecimentos e informações organizados, provenientes de fontes diversas como descobertas instituições (universidades, associações de interesse público ou privado e órgãos governamentais), por onde o conhecimento transita. Além disso, o processo de inovação é influenciado por fatores econômicos, sociais, políticos e organizacionais. Dessa forma, cabe à academia promover a difusão dessa tecnologia e buscar por meio da pesquisa a disseminação do conhecimento.

Uma grande parte dos trabalhos na literatura nacional já explora os aspectos técnicos relacionados ao light wood frame e enfatiza suas vantagens, suas características e a importância para o setor (ARAÚJO et al., 2016; MOLINA; CALIL, 2010; LEITE; LAHR, 2015), dando ênfase ao processo produtivo (KOKUBUN, 2014), a sua viabilidade técnica na construção civil (SILVA, 2015) e a sua viabilidade ambiental (ESPÍNDOLA, 2016) e social (CARDOSO, 2015), explorando sua aceitação pelos usuários (OLIVEIRA, 2014) e comparando o sistema com outros mais tradicionais (GOMES; LACERDA, 2014; PEREIRA; VIEIRA, 2015; SOUZA, 2013). No entanto, não foram encontrados na literatura nacional estudos prospectivos orientados para análise do futuro do light wood frame no mercado brasileiro.

Em pesquisas internacionais nota-se a preocupação com a discussão de estudos futuros e de tendências nessa área, principalmente ao que remete a prédios em LWF na China (QU et al., 2012), na Suécia (HEMSTRÖM; MAHAPATRA; GUSTAVSSON, 2011), na Alemanha, Suécia e Reino Unido (MAHAPATRA; GUSTAVSSON; HEMSTRÖM, 2012) e em toda a Europa (HUMERKOSKI; JONSSON; NORD, 2015), visto que a análise prospectiva é uma forma de gerar vantagens competitivas para os agentes do setor da construção civil.

Dessa forma, o objetivo deste artigo é explorar o potencial do sistema construtivo LWF no Brasil usando a abordagem de cenários prospectivos. A proposta visa analisar as variáveis críticas que devem ser gerenciadas dentro do setor, investigar as necessidades e limitações do sistema construtivo e, por fim, formular estratégias competitivas para a difusão do LWF no país. Por conseguinte, o estudo busca preencher a lacuna no mercado a respeito de análises prospectivas no âmbito da construção civil, mais em específico dos novos sistemas construtivos no Brasil.

Para isso, este artigo utiliza como base o método Cenários Prospectivos e as ferramentas Swot, Delphi e Árvore Morfológica para

científicas e invenções, obtidas através de diferentes métodos e utilizadas na produção de bens e serviços [...]" (CATTANI, 1997) 
operacionalização e condução dos cenários. Os cenários são elaborados considerando um horizonte de análise de 10 anos, sob três perspectivas:
(a) a primeira, pessimista (C1);
(b) a segunda, intermediária (C2); e
(c) terceira, otimista (C3).

Esses cenários são descritos e analisados por especialistas do setor da construção civil de forma que estratégias são formuladas para cada cenário a fim de contribuir efetivamente para a consolidação e a expansão do LWF no Brasil.

\section{Cadeia de construção civil brasileira: o sistema construtivo light wood frame}

Contrariamente ao movimento mundial adepto à construção à base de madeira e a processos mais modulares, que buscam a padronização e a industrialização, já utilizados há várias décadas, no Brasil o sistema construtivo mais utilizado ainda é a alvenaria de blocos (LIGNUM, 2013). Este processo construtivo é caracterizado pela baixa produtividade na execução da obra, pelo domínio técnico centrado na mão de obra executora e, principalmente, pela desconstrução (quebra de paredes para reparos), o que gera desperdício e aumento significativo de resíduos da construção (GOMES; LACERDA, 2014).

Os primeiros protótipos em LWF no Brasil foram iniciativas de construtoras internacionais. O primeiro foi construído em 1973 por Gypsum na região Nordeste do país, com foco principalmente no uso do gesso. Mais tarde, em 2001, o segundo protótipo foi produzido pelo americano $\mathrm{e}$ especialista Alfred Lee Edgar no estado do Rio Grande do Sul. Somente meses mais tarde é que as empresas do ramo madeireiro despertaram o interesse por começar a fabricação de produtos à base de madeira para construção em LWF no país (ARAÚJO et al., 2016).

Uma nova tentativa de implantação do LWF no Brasil aconteceu em 2009, quando a empresa alemã Weinmann em conjunto com o Ministério da Economia do Estado de Baden-Wurttemberg e o Senai convidaram uma delegação de empresários e engenheiros oriundos das regiões Sul e Sudeste do Brasil para conhecer o sistema construtivo em uma viagem à Alemanha. Mais tarde alguns membros desse mesmo grupo juntaram-se a outra viagem técnica, desta vez ao Canadá. A partir dessa experiência, firmou-se o compromisso de estabelecer um projeto para a implantação do sistema no Brasil. Essa comissão, chamada de
"Casa Inteligente”, tinha como objetivo trabalhar em cinco frentes:

(a) normalização do sistema no Brasil;

(b) uso da matéria-prima de maneira sustentável e racional;

(c) busca de financiamentos para fomento do LWF no Brasil; capacitação da mão de obra; e

(d) visibilidade do sistema construtivo no país (marketing) (FEDERAÇÃO..., 2017).

Nesse mesmo período o governo brasileiro propôs uma inciativa para a expansão do setor da construção civil a fim de combater o déficit habitacional, que chegava a 15\% (TEREZO, 2011). Entre as iniciativas governamentais destacam-se os grandes investimentos na infraestrutura do setor e a facilidade do crédito para financiamento imobiliário (CONSTRUÇÃO..., 2011), além de fomentos já existentes, como o Programa Brasileiro da Qualidade e Produtividade do Habitat (PBQP-H), que tem como principal objetivo organizar o setor da construção civil a partir da melhoria da qualidade do habitat e da modernização produtiva (PROGRAMA..., 2016).

Com todos esses movimentos acontecendo no Brasil, os primeiros empreendimentos nessa área começaram a intensificar-se. Em 2013 o primeiro condomínio residencial, com 280 unidades de 45 $\mathrm{m}^{2}$, foi financiado pelo governo através do programa "Minha Casa, Minha Vida", que ainda não havia financiado obras em LWF. Esse empreendimento foi construído pela Construtora Roberto Ferreira em parceria com uma empresa fabricante de kits em LWF, a Tecverde (ARAÚJO et al., 2016). Com essas iniciativas outros projetos começaram a aparecer por todo o país, principalmente nas regiões Sudeste e Sul, onde se encontram os principais fornecedores de madeira serrada para a construção em madeira. Segundo Araújo et al. (2016), em 2016, no Brasil, 22 empresas, entre elas serrarias, construtoras e escritórios, atuavam no ramo de LWF de forma direta.

No entanto, para que esses projetos residenciais pudessem obter financiamento pelo governo brasileiro, várias barreiras tiveram de ser superadas. Muitos testes foram realizados a fim de averiguar a resistência mecânica das peças, sua capacidade acústica e térmica, e a resistência ao fogo. Em 2011 foi aprovada a primeira diretriz brasileira sobre o tema, a Sinat $n^{\circ} 005$, elaborada para sistemas construtivos estruturados em peças de madeira maciça serrada. Mais tarde, em 2013, a empresa Tecverde conseguiu desenvolver um documento técnico para construções habitacionais de casas térreas utilizando o sistema leve construtivo 
(BRASIL, 2015). Esse documento foi renovado em 2015, depois de ter passado por uma série de ensaios e simulações para atendimento à norma brasileira NBR 15575 e demais normas. O processo de normatização do LWF no Brasil segue acelerado em 2017, e existe grande expectativa no setor, visto que a falta de normatização contribui para a insegurança por parte dos usuários finais do sistema construtivo (FINATTI, 2014).

Além desses limitantes, a literatura nacional apresenta outros fatores críticos que vêm influenciando de forma negativa a difusão do LWF no país. O primeiro deles é o preconceito com o material madeira. A madeira, por ser explorada há muitos anos no país e utilizada muitas vezes de forma errônea, é considerada um produto de baixa qualidade. A falta de credibilidade por parte dos brasileiros com relação a esse material e o receio do risco de degradação biológica, mesmo com tratamento, é uma das grandes barreiras relatadas na literatura (MOLINA; CALIL, 2010). Mesmo com a produção sustentável de florestas plantadas, há também o receio de existir o desmatamento de florestas nativas.

Corroborando com essa barreira cultural, poucos são os profissionais na área da construção civil que detêm conhecimento com relação ao uso na madeira para edificações (OLIVEIRA, 2014). Portanto, para Molina e Calil (2010), a falta da conscientização e educação de engenheiros e arquitetos da necessidade e potencial da utilização desse sistema construtivo no Brasil ainda é muito grande, além de existir nesse meio percepções negativas em relação às propriedades da madeira.

Outra limitação identificada na literatura está relacionada com o próprio setor de construção civil. Segundo Mahapatra, Gustavsson e Hemström (2012), na prática o setor conduz à escolha de seus insumos e das técnicas construtivas em detrimento de normas, instituições e investimento em infraestrutura já existente, ao conhecimento e ao grande número de agentes (proprietários, projetistas, empreiteiros e fornecedores) dentro da cadeia de suprimento do setor. Dessa forma, como o setor da construção civil no Brasil, em sua grande parte, é baseado na alvenaria, poucos são os fornecedores e prestadores de serviço que atuam tendo a madeira no centro do processo, e a grande maioria destes são empresas estrangeiras, o que resulta na elevação do custo da edificação (CARDOSO, 2015).

Ainda a respeito dos insumos do LWF, nem toda madeira produzida no Brasil pode ser utilizada para fins construtivos. Segundo a diretriz em vigor (BRASIL, 2015), a madeira usada para LWF deve ser tratada de forma adequada e deve apresentar boa qualidade, ou seja, não apresentar defeitos que interfiram em sua resistência mecânica. Além disso, suas dimensões devem ser consideráveis para ser industrializada na concepção de painéis estruturais. Essas limitações reduzem a oferta de matéria-prima e fornecedores no Brasil. A boa notícia é que, segundo o Sistema Nacional de Informações Florestais (SNIF), de 2013 a 2014 o crescimento do setor de madeira serrada para fins construtivos foi de $48 \%$.

Outro fator de destaque é a necessidade da mão de obra qualificada no sistema construtivo LWF. Segundo Kokubun (2014), é essencial para as operações de fabricação de painéis e de montagem e desmontagem da estrutura o uso de mão de obra qualificada. Na alvenaria essa não é uma exigência. Dessa forma, Ferreira (2014) salienta que a oferta de mão de obra é pequena, além de existir a necessidade de capacitar os funcionários e trazê-los do setor madeireiro.

Segundo Araújo et al. (2016), já existe há mais de 30 anos no Brasil universidades, laboratórios e centros de pesquisas que trabalham com estudos em estruturas de madeiras. Diversas iniciativas foram realizadas no meio acadêmico, inclusive um curso foi criado para suprir essa necessidade e disseminar mais a industrialização da madeira em todo o país. Entretanto, ainda há pouca informação a respeito do sistema na literatura nacional. Para Oliveira (2014), é preciso que o governo brasileiro se envolva mais, promova mais campanhas de marketing e gere mais incentivos financeiros para a difusão do sistema no país.

\section{Método}

A pesquisa, de caráter qualitativo, tem como objetivo explorar o potencial do sistema construtivo LWF no Brasil. Para isso se trabalhou com duas fontes de informações, a literatura nacional e a consulta a especialistas da área. Optou-se por conduzir a pesquisa dessa forma em virtude de o assunto possuir alto grau de incerteza, visto que o sistema construtivo ainda está sendo difundindo no Brasil e poucas são as informações científicas quanto ao LWF no país. Os próprios agentes da cadeia produtiva que atuam de forma direta são poucos. Além disso, a maior parte das informações nacionais é oriunda de fontes tais como: jornais, revistas e reportagens.

Dessa forma, foram escolhidos para participar da atividade os representantes da cadeia de suprimentos do LWF (Quadro 1). A amostra adotada é de caráter não probabilístico e realizada por conveniência. Os especialistas foram selecionados com base em sua atuação e experiência na área. 
Esses são pesquisadores de universidades e profissionais que atuam em sindicatos, associações e no meio corporativo. Os critérios para escolha dos especialistas foram três: experiência direta com sistema construtivo, tempo de pesquisa na área e disponibilidade para participar do estudo prospectivo. Vale ressaltar que um grupo com 20 especialistas da área foi consultado para participar da pesquisa, mas apenas 5 tiveram interesse e disponibilidade para participar do estudo prospectivo.

Esta pesquisa buscou responder a duas perguntas:

(a) Quais são as variáveis críticas que afetam a difusão e o potencial do LWF no Brasil atualmente e nos próximos 10 anos?

(b) Quais são as estratégias mais pertinentes para maior difusão do LWF no Brasil?

No primeiro momento foi fornecida aos especialistas uma breve explicação do estudo, apresentando a necessidade de se conhecer mais sobre os fatores que vêm influenciando de forma direta a expansão do LWF no Brasil. Em seguida as ferramentas prospectivas foram implantadas com a proposta de elaborar os cenários prospectivos. Os cenários elaborados são classificados como contrastantes, pois buscam, por um período no tempo, investigar o contexto e descrever diferentes situações a partir de variações de cada fator crítico identificado. As etapas seguidas para a condução da pesquisa podem ser visualizadas na Figura 1.

$\mathrm{Na}$ primeira etapa (Elaboração da Swot) os especialistas identificaram as forças, as fraquezas, as ameaças e as oportunidades que norteiam o sistema LWF no Brasil. Num primeiro momento cada especialista pôde dar seu ponto de vista e, em seguida, as respostas foram compartilhadas. Mais adiante, com as informações da matriz Swot, os especialistas foram desafiados a identificar as variáveis críticas que influenciam a difusão do LWF no Brasil. Para isso se utilizou a técnica Delphi (segunda etapa do estudo). Após alcançar um consenso entre as variáveis críticas, os autores da pesquisa coletaram as informações e, por meio de uma análise, foram elaboradas para cada variável as possíveis hipóteses, conduzindo o estudo para a elaboração dos cenários prospectivos.

\section{Quadro 1 - Especialistas participantes do estudo prospectivo}

\begin{tabular}{|c|l|c|l|}
\hline Esp. & \multicolumn{1}{|c|}{ Ramo de pesquisa } & Tempo com LWF & \multicolumn{1}{c|}{ Formação } \\
\hline A & $\begin{array}{l}\text { Empresa fabricante de } \\
\text { LWF no Brasil desde 2009 }\end{array}$ & Desde 2010 & Mestre na área de engenharia ambiental \\
\hline B & $\begin{array}{l}\text { Sindicato da indústria de } \\
\text { Construção Civil }\end{array}$ & Desde 2008 & Economista/Engenheiro Civil \\
\hline C & Pesquisador acadêmico & Desde 2012 & Doutor na área de arquitetura e urbanismo \\
\hline D & $\begin{array}{l}\text { Fornecedor de insumos } \\
\text { para fabricação de LWF } \\
\text { no Brasil desde 2008 }\end{array}$ & Desde 2011 & Arquiteto e Urbanista \\
\hline E & $\begin{array}{l}\text { Associação de empresas } \\
\text { de base florestal }\end{array}$ & Desde 2009 & Doutor na área de engenharia florestal \\
\hline
\end{tabular}

\section{Figura 1 - Etapas para a condução do estudo prospectivo}

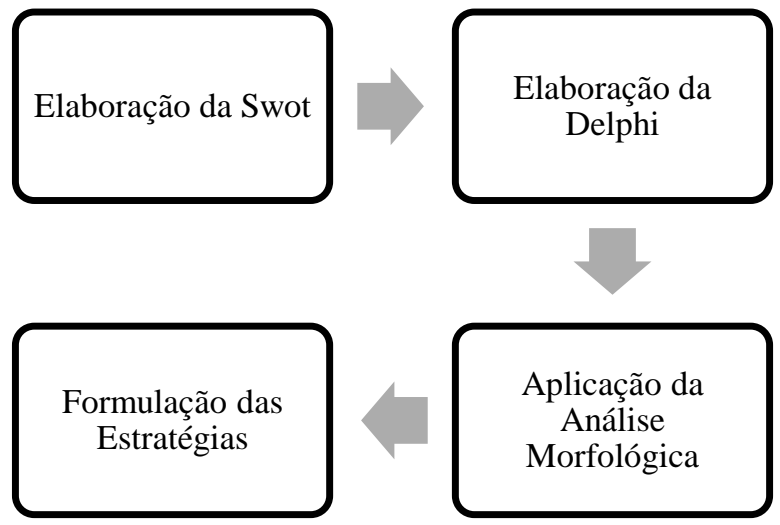


Com as possibilidades elaboradas, a terceira etapa foi aplicada, em que cada especialista pôde, por meio da Árvore Morfológica, fazer o cruzamento das hipóteses mais plausíveis, considerando o horizonte de pesquisa de 10 anos. Para finalizar essa etapa, novamente os especialistas compartilharam suas respostas e, por meio de uma discussão, um consenso com relação aos três cenários prospectivos foi estabelecido.

De posse dos cenários, os especialistas passaram à quarta e última etapa: formulação das estratégias. Para cada cenário os especialistas foram desafiados a refletir, com base em seu contexto de atuação, sobre quais ações deveriam ser estabelecidas considerando a aproximação de um cenário mais pessimista (C1), intermediário (C2) e/ou mais otimista (C3). O estudo teve duração de 6 semanas. As informações foram recebidas via e-mail, e as interações ocorreram via Web.

\section{Resultados}

\section{Primeira etapa: aplicação da Swot}

A pesquisa iniciou com a proposta de conhecer o estado atual do LWF no Brasil. Para isso foram consultadas fontes diversas na literatura (artigos científicos, artigos de journals e notícias do mercado e do setor de construção civil) do país.

Com essas informações foi possível elaborar, em conjunto com os especialistas, a matriz Swot, que apresenta os pontos fortes, fracos, ameaças e oportunidades do LWF no Brasil. A proposta buscou mapear a situação atual no país ao listar os fatores essenciais que norteiam hoje a difusão desse sistema construtivo. O Quadro 2 mostra a matriz estabelecida.

Esta análise serviu como início de reflexão do atual cenário do LWF no Brasil, haja vista que muitos pontos citados na literatura também foram identificados e salientados pelos especialistas.

\section{Segunda etapa: aplicação da Delphi}

De posse das informações coletadas na literatura nacional (referencial teórico) e com os especialistas do setor de construção civil, a técnica Delphi foi aplicada. O objetivo dessa atividade foi identificar quais variáveis críticas deveriam ser conhecidas e gerenciadas para a elaboração de cenários prospectivos para o setor da construção civil, considerando uma prospecção do setor para os próximos 10 anos.

No primeiro momento foi enviada aos participantes uma lista com as variáveis identificadas na literatura. Essas informações foram retiradas de trabalhos identificados na literatura nacional. Esses artigos apresentam o LWF no Brasil e suas principais características (Quadro 3).

Em seguida, os especialistas analisaram as variáveis e tiveram a oportunidade de apresentar outras consideradas importantes para ser geridas. As variáveis listadas por eles foram:

(a) variação das necessidades técnicas para construção conforme as diferentes regiões brasileiras;

(b) seguro das edificações em LWF no Brasil; e

(c) financiamento de construções em LWF.

Essas variáveis foram identificadas ainda na matriz Swot, mas não haviam sido identificadas na literatura nacional.

Num terceiro momento os especialistas foram convidados a selecionar entre essas variáveis apenas as dez mais críticas para estudo. Os fatores culturais/sociais que continham três variáveis foram reajustados, visto que os especialistas consideraram-nas fatores muito próximos. Dessa forma, decidiu-se organizá-las em duas variáveis, como é possível visualizar no Quadro 4.

Os especialistas puderam, mediante o anonimato, apresentar sua opinião com relação a cada variável identificada, e por meio do envio das respostas pelos pesquisadores todos tiveram acesso às respostas estabelecidas ao longo das rodadas. Assim, os especialistas chegaram ao consenso de que as variáveis que deveriam ser gerenciadas e conhecidas a fim de se estudarem os cenários prospectivos foram as apresentadas no Quadro 4.

\section{Terceira etapa: aplicação da Árvore Morfológica}

Dada as variáveis selecionadas pelos especialistas, as hipóteses com relação às possibilidades existentes para cada variável foram geradas a fim de que fosse selecionadas as opções mais plausíveis considerando os três cenários propostos neste trabalho: um cenário pessimista (C1), um intermediário (C2) e um mais otimista (C3). No Quadro 5 é possível visualizar as hipóteses geradas pelos pesquisadores, criadas pensando nas possibilidades para cada variável identificada.

É importante destacar que o mais importante nessa atividade não é acertar as previsões, e sim buscar as reflexões que poderão contribuir para a tomada de decisões em um futuro próximo (GODET, 1986). A proposta é gerar os cenários e tornar as reflexões mais claras com relação ao tema estudado. 
Quadro 2 - Matriz Swot

\begin{tabular}{|c|c|}
\hline Ameaças & Oportunidades \\
\hline $\begin{array}{l}\text { Soluções técnicas: as soluções técnicas adotadas } \\
\text { precisam de revisão conforme as diferentes regiões do } \\
\text { país, para garantir o total desempenho deste sistema. } \\
\text { Crise no setor construção civil: o mercado de } \\
\text { construção civil brasileiro é fortemente afetado pela } \\
\text { crise política e econômica do país. } \\
\text { Resistência: há grande resistência em mudar a cultura } \\
\text { brasileira para que confie e queira esse sistema em suas } \\
\text { casas. } \\
\text { Transformação de fornecedores em concorrentes: como } \\
\text { não existe exclusividade com os parceiros e } \\
\text { fornecedores, estes podem colaborar com a } \\
\text { concorrência ou se tornar concorrentes. }\end{array}$ & $\begin{array}{l}\text { Concorrência: quanto maior a concorrência do } \\
\text { sistema construtivo, melhor para o consumidor } \\
\text { final (vantagem para a população), pois permite } \\
\text { diminuir o preço e proporciona mais } \\
\text { possibilidades de componentes/elementos } \\
\text { disponíveis no mercado, inclusive garantindo } \\
\text { flexibilidade. } \\
\text { Expansão dos programas de financiamento } \\
\text { habitacional: abertura de novas oportunidades. } \\
\text { Desde } 2014 \text { o Governo Federal autorizou a } \\
\text { utilização do sistema wood frame na construção } \\
\text { de moradias no programa habitacional Minha } \\
\text { Casa, Minha Vida. } \\
\text { Nicho de mercado: o wood frame é pouco } \\
\text { explorado localmente. } \\
\text { Preocupação da sociedade com questões } \\
\text { ambientais: há preocupação crescente com as } \\
\text { questões ambientais e com o impacto do atual } \\
\text { estilo de vida nas gerações futuras. } \\
\text { Déficit habitacional: apesar do setor em crise, } \\
\text { ainda existe no país déficit habitacional, } \\
\text { sobretudo nas classes C e D. }\end{array}$ \\
\hline Força & Fraqueza \\
\hline $\begin{array}{l}\text { Tempo da obra: tempo de produção é menor se } \\
\text { comparado com a alvenaria. } \\
\text { A maior parte da construção é industrializada: além da } \\
\text { economia de tempo, a industrialização da construção } \\
\text { permite o controle da qualidade do serviço, a } \\
\text { padronização dos processos e a redução no consumo de } \\
\text { materiais. } \\
\text { Sustentabilidade: a utilização de uma matéria-prima } \\
\text { renovável (madeira) tem grande apelo na questão da } \\
\text { sustentabilidade. Além da madeira, a empresa aplica os } \\
\text { conceitos da sustentabilidade em toda a obra, com } \\
\text { sistemas de captação de água de chuva, instalação de } \\
\text { placas fotovoltaicas, entre outras tecnologias que trazem } \\
\text { maior conforto ambiental. } \\
\text { Integração entre equipe de projeto e execução da obra: a } \\
\text { oferta do projeto e da execução da obra pela mesma } \\
\text { empresa é uma facilidade para o cliente. } \\
\text { Proximidade dos fornecedores de madeira: as regiões } \\
\text { Sul e Sudeste têm como vantagem os fornecedores de } \\
\text { madeira reflorestada situados principalmente nessas } \\
\text { regiões. } \\
\text { Contratos fechados: o cliente sabe exatamente o custo } \\
\text { da obra. }\end{array}$ & $\begin{array}{l}\text { Falta de conhecimento/preconceito: devido } \\
\text { principalmente à falta de informações quanto à } \\
\text { vida útil, à resistência dos materiais e à } \\
\text { impermeabilização, existe grande resistência da } \\
\text { população em relação à utilização da madeira e } \\
\text { de novas tecnologias para a construção de } \\
\text { moradias, o que dificulta a expansão desse } \\
\text { sistema. } \\
\text { Seguros de edificações em LWF: por ter como } \\
\text { principal componente a madeira, poucas são as } \\
\text { empresas de seguros para esse tipo de imóvel. } \\
\text { Proximidade dos fornecedores de madeira: as } \\
\text { regiões Norte e Nordeste têm como desvantagem } \\
\text { a distância dos fornecedores de madeira } \\
\text { certificada. } \\
\text { Falta de normas: o sistema construtivo LWF } \\
\text { possui até o momento apenas diretrizes, e não } \\
\text { normas que regem sua conduta. Isso vem } \\
\text { gerando preconceito. }\end{array}$ \\
\hline
\end{tabular}




\section{Quadro 3 - Variáveis identificadas na literatura}

\begin{tabular}{|c|c|}
\hline Fatores & Variáveis críticas identificadas na literatura \\
\hline \multirow{3}{*}{ 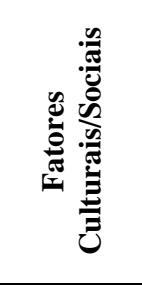 } & Aceitação da madeira no ambiente construído por parte dos usuários. \\
\hline & $\begin{array}{l}\text { Falta de conhecimento por parte dos profissionais com relação ao material madeira e } \\
\text { com relação ao próprio sistema LWF. }\end{array}$ \\
\hline & $\begin{array}{l}\text { Percepções negativas dos profissionais da indústria da construção em relação às } \\
\text { propriedades da engenharia da madeira/falta de conscientização e educação de } \\
\text { engenheiros e arquitetos da necessidade e potencial da utilização desse sistema } \\
\text { construtivo no Brasil. }\end{array}$ \\
\hline \multirow{6}{*}{ 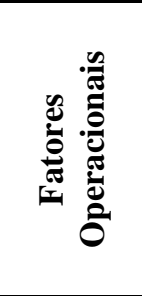 } & Falta de tecnologia no Brasil. \\
\hline & Falta de integração da cadeia de suprimentos do setor da construção civil. \\
\hline & Alta rotatividade de funcionários/turnover no setor. \\
\hline & Mão de obra especializada/capacitada. \\
\hline & Madeira de qualidade e/ou tratada e/ou certificada para fabricação dos frames. \\
\hline & $\begin{array}{l}\text { Falta de fornecedores de insumos no Brasil. A maior parte dos fornecedores são } \\
\text { estrangeiros. }\end{array}$ \\
\hline \multirow{5}{*}{ 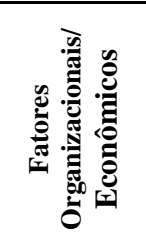 } & Ausência de normas brasileiras. \\
\hline & $\begin{array}{l}\text { Falta de incentivo/interesse do setor da construção civil e do governo brasileiro em } \\
\text { adotar o LWF (marketing/financiamento). }\end{array}$ \\
\hline & Termos técnicos usados na grande maioria em língua inglesa. \\
\hline & Poucas informações na literatura nacional. \\
\hline & Concorrências com outros sistemas construtivos mais tradicionais. \\
\hline \multirow{2}{*}{ Ambiental } & existir desmatamento da floresta nativa. \\
\hline & recursos e eficiência energética. \\
\hline
\end{tabular}

\section{Quadro 4 - Variáveis críticas selecionadas pelos especialistas}

\begin{tabular}{|c|l|}
\hline \multicolumn{2}{|c|}{ Variáveis Críticas selecionadas } \\
\hline 1 & $\begin{array}{l}\text { Aceitação da madeira no ambiente construído por parte dos usuários. Falta mostrar ao público } \\
\text { comprador todos aspectos positivos que o uso da madeira pode trazer, como, por exemplo: menor } \\
\text { quantidade de resíduos, conforto térmico maior, construção em ambiente fabril que vai resultar em } \\
\text { melhor controle da execução da edificação, entre outros }\end{array}$ \\
\hline 2 & $\begin{array}{l}\text { Falta de conhecimento por parte dos profissionais com relação ao material madeira e com relação ao } \\
\text { próprio sistema LWF/ Falta de conscientização e educação de engenheiros e arquitetos da } \\
\text { necessidade e potencial da utilização desse sistema construtivo no Brasil. Percepções negativas dos } \\
\text { profissionais da indústria da construção em relação às propriedades da engenharia da madeira }\end{array}$ \\
\hline 3 & Madeira de qualidade e/ou tratada e/ou certificada para fabricação dos frames \\
\hline 4 & Mão de obra especializada/capacitada \\
\hline 5 & Ausência de normas brasileiras \\
\hline 6 & Financiamento de construções em LWF \\
\hline 7 & $\begin{array}{l}\text { Falta de incentivo/interesse do setor da construção civil e do governo brasileiro em adotar o LWF } \\
\text { (Marketing/Financiamento) }\end{array}$ \\
\hline 8 & Falta de integração da cadeia de suprimentos do setor da construção civil \\
\hline 9 & Seguro das edificações em LWF no Brasil \\
\hline 10 & Concorrências com outros sistemas construtivos mais tradicionais \\
\hline
\end{tabular}

Nessa atividade os especialistas foram orientados a selecionar as hipóteses pensando no período de 10 anos. Vale ressaltar que, mesmo em cenários pessimistas, algumas variáveis podem ainda apresentar hipóteses extremamente otimistas, visto que há ações que estão sendo realizadas dentro do setor da construção civil para difusão do LWF que podem ser promissoras. Com esse raciocínio é que os especialistas apresentaram sua opinião. Cada integrante, no primeiro momento, apresentou seu ponto de vista e depois um consenso foi estabelecido para a elaboração dos três cenários. Um resumo breve de cada cenário elaborado é apresentado no Quadro 5. 


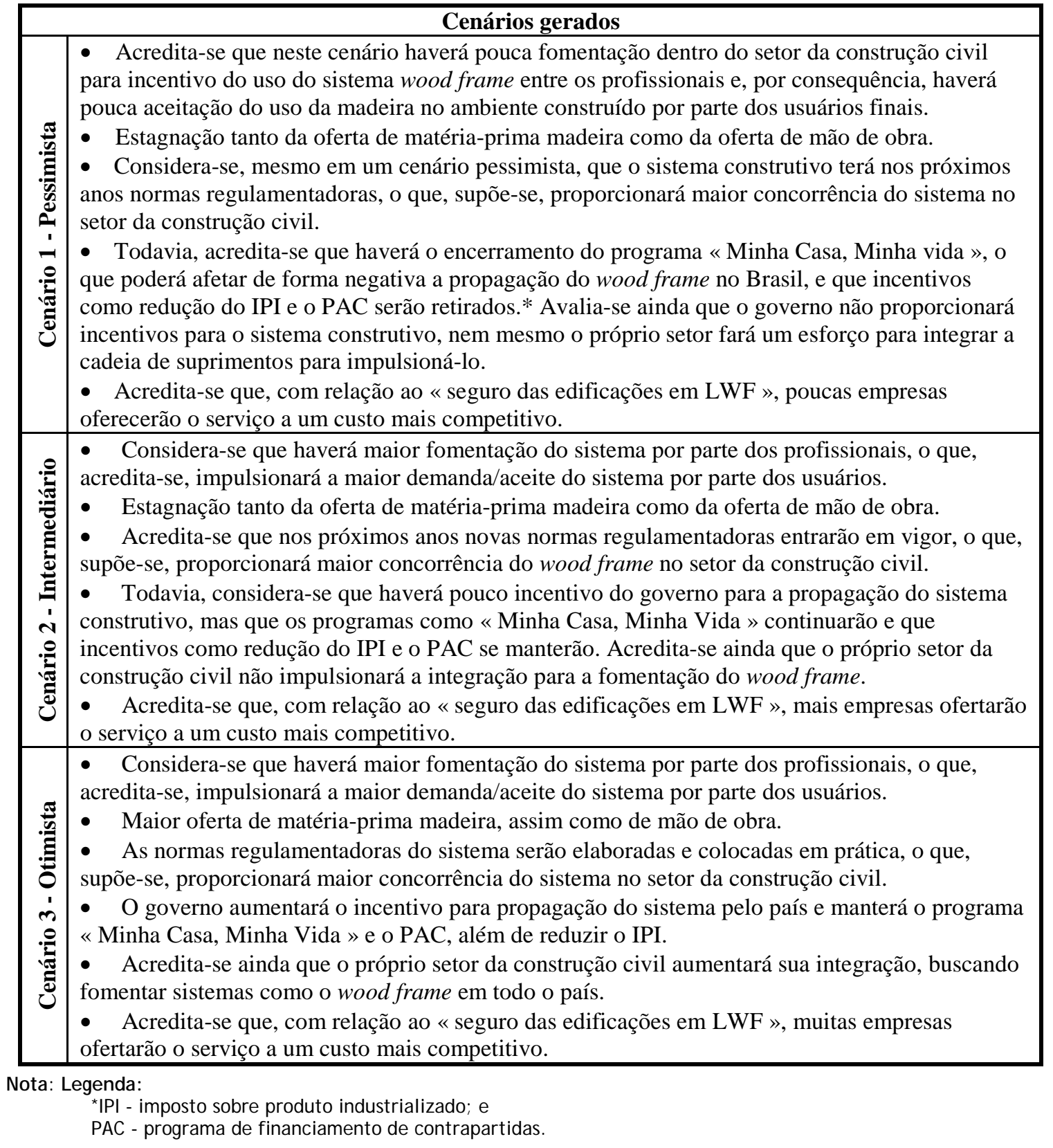

Percebe-se que os cenários elaborados bem como as principais variáveis críticas que influenciam a difusão LWF estão relacionados com o ambiente operacional e com as características do sistema LWF. Em primeiro lugar, o sucesso da difusão LWF é fortemente dependente do ambiente regulador, especialmente em termos de remoção dos obstáculos regulamentares, ou seja, preconceito dos usuários, falta de formação dos profissionais, falta de normalização do sistema e apoio do governo e da própria cadeia de suprimentos dos setores da construção civil e madeireiro.

Em segundo lugar, seria necessária mais concorrência no setor da LWF para abaixar os custos e para fazer as práticas do LWF mais credíveis aos olhos dos profissionais de arquitetura, engenheiros e prestadores de serviços. Por outro lado, também seria importante a integração dos agentes da cadeia de suprimentos com a proposta de diminuir a barreira empresarial.

Acredita-se que a difusão do LWF em larga escala pode resultar em mudanças na demanda por recursos de madeira, embora mais pelo caráter do que em volume. Ou seja, em vez de grandes aumentos na demanda de madeira em tora, a difusão de LWF implicaria mudança em direção a graus mais elevados de qualidade e maiores propriedades técnicas da madeira produzida, o que também pode 
afetar positivamente o valor acrescentado da indústria de madeira.

Devido à complexidade do ambiente operacional, os três cenários são vinculados apenas para servir ao pensamento crítico sobre os tipos de mudanças que precisam ocorrer para a difusão do LWF. Isso é, eles não podem ser considerados como as únicas alternativas para o desenvolvimento futuro. Mesmo assim, os cenários transmitem uma mensagem importante: o futuro potencial para LWF é dependente de interações e decisões tomadas em vários níveis no ambiente operacional. Algumas das possíveis alterações decorrem da necessidade de abordar questões globais de sustentabilidade e questões relacionadas com a informação e a educação, o que corrobora as ideias de Humerkoski, Jonsson e Nord (2015).

Acredita-se ainda que, para o LWF chegar à consolidação plena no Brasil, ele precisa atingir uma massa crítica de interesse em cada parte da cadeia de valor da construção, ou seja, entre os setores florestais e madeireiros, os empreiteiros, arquitetos e engenheiros, e, finalmente, entre os usuários finais.

\section{Quarta etapa: estratégias geradas para difusão do sistema considerado um horizonte de 10 anos}

A partir dos cenários elaborados, um resumo de cada um foi enviado novamente aos especialistas, que tiveram como atividade elaborar estratégias específicas para eles. Para isso, a seguinte questão foi apresentada: se nos próximos anos um dos cenários C1/C2/C3 for o mais próximo da realidade, quais deveriam ser as estratégias que «nós » do setor da construção civil (acadêmicos, profissionais, pesquisadores, empresários) deveríamos tomar hoje para mantê-lo competitivo, buscando a fomentação e consolidação do sistema construtivo light wood frame no Brasil?

Sendo assim, cada especialista, em seu campo de trabalho, apresentou estratégias consideradas por eles relevantes de ser aplicadas no contexto atual (Quadro 6).

\section{Quadro 6 - Estratégias geradas pelos especialistas}

\begin{tabular}{|c|c|}
\hline \multicolumn{2}{|r|}{ Estratégias geradas } \\
\hline Cenário 1 & $\begin{array}{l}\text { - Desenvolvimento de uma política setorial de florestas plantadas em consonância } \\
\text { com a cadeia produtiva do LWF } \\
\text { • } \quad \text { Articulação setorial para a inserção do LWF em editais de obras govenamentais. } \\
\text { Mais incentivo para o Programa Minha Casa, Minha Vida estimular obras com novos } \\
\text { sistemas construtivos } \\
\text { - } \quad \text { Articulação setorial para apresentar as vantagens competitivas do sistema (preço, } \\
\text { prazo, controle, eficiencia no uso de recursos, potencial natural do Brasil para construção } \\
\text { com madeira plantada } \\
\text { - } \quad \text { Criação e estímulos aos cursos profissionais (nível técnico e superior) relacionados à } \\
\text { cadeia } \\
\text { - } \quad \text { Acordos com governo e com o setor para reduzir custos adminstrativos (impostos) }\end{array}$ \\
\hline Cenário 2 & $\begin{array}{l}\text { - Articulação setorial para viabilizar programas de pesquisas na área de tecnologia da } \\
\text { madeira, novos produtos, inovação, preservação da madeira, estruturas da madeira } \\
\text { - } \quad \text { Pesquisa de sistemas de manejo e melhoramento genético para atendimento de nova } \\
\text { demanda; } \\
\text { - } \quad \text { Elaboração de leis que estimulem o uso de construções sustentáveis } \\
\text { - } \quad \text { Ações de relacionamento setorial } \\
\text { - } \quad \text { Com a norma em vigor, deveria existir uma unidade curricular específica nos cursos } \\
\text { superiores de Engenharia Civil e Arquitetura para o wood frame } \\
\text { - } \quad \text { Maiores incentivos à mão de obra qualificada para o trabalho com wood frame }\end{array}$ \\
\hline Cenário 3 & 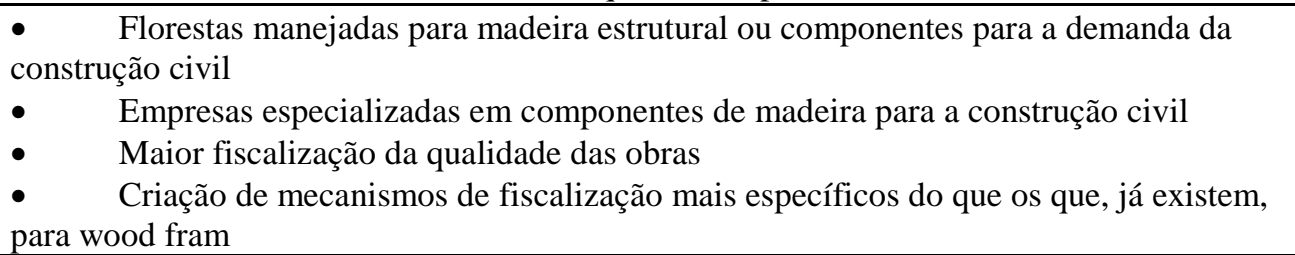 \\
\hline
\end{tabular}


Em um cenário pessimista, os subsídios do governo serão minimizados para o setor habitacional, sem programas específicos. Como consequência, a execução de obras em maior escala, como vinha ocorrendo, cessará, afetando toda a cadeia de produção. Portanto, novas medidas públicas estatais deveriam ser tomadas para facilitar a implementação desse sistema inovador em madeira. Neste caso, acredita-se que seja necessária articulação setorial para apresentar as vantagens competitivas do sistema; seriam necessários o desenvolvimento do setor madeireiro para estimular o uso da madeira para construção civil e acordos legais que diminuam a burocratização e os custos administrativos (impostos) dessas execuções perpassando em todos os níveis desta cadeia produtiva, com foco especialmente nas madeiras de florestas plantadas, para favorecer o mercado interno. Assim, com esses facilitadores para as empresas construtoras, a mão de obra e a matériaprima poderão ser impulsionadas. Em paralelo, deverá haver incentivo e parceria entre Estado, indústrias e universidades para implementar o ensino dessa técnica nos cursos profissionalizantes, tanto em nível técnico quanto em níveis superiores, mesmo que ainda em unidades curriculares optativas.

Em um cenário mais intermediário, seria necessário intensificar a pesquisa e desenvolvimento de produtos e insumos para light wood frame, pois neste cenário o setor já em expansão deveria buscar o aperfeiçoamento e o desenvolvimento tecnológico no país, expandir o estímulo de novos sistemas construtivos dentro da cadeia de suprimentos da construção civil através de leis governamentais e buscar relações mais próximas entre os agentes da cadeia de suprimentos para expansão da tecnologia.

Neste cenário a norma do light wood frame estaria em vigor. Dessa forma, acredita-se que o Conselho de Arquitetura e Urbanismo (CAU) e o Conselho Regional de Engenharia e Agronomia (CREA) deveriam exigir a implantação de uma unidade curricular específica nos cursos superiores de Engenharia Civil e Arquitetura para o sistema LWF. Ou, no mínimo, sugere-se incluir esse sistema na ementa das unidades curriculares de estruturas de madeira (recomendando a separação dessa unidade curricular com as demais estudadas).

Com relação ao aspecto de mão de obra da fábrica, salienta-se a inclusão no ensino de engenharias de produção e industrial madeireira, para avançar as técnicas de execução com a possiblidade de criação/inovação de maquinários nacionais para esse fim. Também, para o treinamento de operários da fábrica e do canteiro, são necessários cursos técnicos profissionalizantes com assuntos específicos e de curta duração.
Considerando um cenário mais otimista, acredita-se na intensa especialização dos profissionais e no aumento da pesquisa. Com o mercado muito aquecido, haveria mais concorrência e, assim, tendência de diminuir os preços das construções para poder competir no mercado. Para manter seus lucros, alguns poderiam baixar o nível de qualidade dos produtos, tentando diminuir os custos de produção. Portanto, neste cenário seria pertinente existir maior fiscalização para manter a qualidade das construções. Com a norma em vigência, seria pertinente ainda fiscalizar a qualidade de cada produto e a execução na fábrica e no canteiro. Criar uma associação das construtoras em madeira (ou específico para o light wood frame) poderia ser uma solução para fazer com que essa fiscalização seja mais específica (além de CREA, CAU e agentes de financiamento e de seguro já existentes).

\section{Comparativo com trabalhos correlacionados}

Outros trabalhos na literatura vêm buscando identificar os pontos fortes e fracos da difusão do LWF em todo o mundo. No Brasil a pesquisa é recente e o objeto de estudo ainda é a difusão técnica de forma geral. Nos quatro trabalhos identificados na literatura estrangeira, o foco da difusão é mais específico para construção de prédios em LWF. Porém, percebe-se similaridade entre os trabalhos com relação aos pontos fortes e fracos da difusão do sistema. O Quadro 7 apresenta os trabalhos.

Esses estudos apresentam os pontos fortes identificados na literatura para difusão do LWF. Os pontos similares identificados nos trabalhos foram:

(a) o incentivo do governo por meio de programas de financiamento e/ou pesquisa para utilização de técnicas mais sustentáveis; e

(b) as características promissoras do LWF referentes a flexibilidade, rapidez, redução de resíduos, entre outros, conforme o Quadro 8.

Com relação aos pontos fracos, seis fatores destacam-se fortemente (Quadro 9). O primeiro faz referência à falta de profissionais qualificados ou que tenham interesse em atuar na área de forma direta.

O segundo fator está relacionado com a cadeia de suprimentos. Segundo os trabalhos, a cadeia de suprimentos está muito fechada para novas tecnologias em função da necessidade de investir em infraestrutura para atender a um novo mercado. Esse segundo fator está relacionado com o terceiro, que faz referência ao preconceito com relação às propriedades físicas e mecânicas da madeira (resistência, estabilidade, durabilidade e vida útil) 
por parte dos agentes da cadeia de suprimentos, o que dificulta a competição com outras técnicas construtivas. Ou seja, percebe-se que, se a cadeia de suprimentos não está preparada para atender a um novo sistema construtivo e se ela ainda não tem interesse na difusão, o sistema fica mais comprometido.

O quarto fator mais identificado é a tradição do uso do concreto para construção civil em edificações em geral (Brasil) e em prédios (nos outros estudos). Como a alvenaria é uma técnica consolidada, a cadeia de suprimentos já está pronta para atendê-la, assim como seus profissionais estão capacitados. Estes dois fatores impactam de forma negativa a consolidação do LWF.

O quinto fator negativo está relacionado com necessidade de normatizar o sistema construtivo, identificada não somente no Brasil, mas também no trabalho de Mahapatra, Gustavsson e Hemström (2012) e Humerkoski, Jonsson e Nord (2015). E, por fim, o sexto fator está relacionado com a dificuldade em padronizar a técnica em todas as regiões. Os códigos de construção e sua interpretação podem variar de uma região para outra, o que causa dificuldades em encontrar as melhores práticas operacionais. Além disso, os aspectos técnicos podem ser influenciados pelo clima da região e pelo tipo de madeira utilizada.

Além dos pontos fortes e fracos identificados nesses trabalhos, as pesquisas trouxeram também reflexões quanto às estratégias possíveis para intensificar as atividades do LWF. O Quadro 10 mostra que essas ações são bem similares às identificadas neste estudo de caso.

\section{Quadro 7 - Estudos similares na área da difusão do LWF no mundo}

\begin{tabular}{|l|l|l|l|}
\hline \multicolumn{1}{|c|}{ Pesquisas } & \multicolumn{1}{|c|}{ Objetivo } & \multicolumn{1}{c|}{ Método de pesquisa } & \multicolumn{1}{c|}{ Especialistas } \\
\hline Estudo atual & $\begin{array}{l}\text { Identificar as variáveis que } \\
\text { influenciam a difusão do LWF } \\
\text { no Brasil e através destas gerar } \\
\text { cenários prospectivos }\end{array}$ & $\begin{array}{l}\text { Estudo prospectivo- com } \\
\text { especialistas e informações } \\
\text { de fontes secundárias } \\
\text { (Qualitativo) }\end{array}$ & $\begin{array}{l}\text { Especialistas na area } \\
\text { da construção civil e } \\
\text { florestal }\end{array}$ \\
\hline $\begin{array}{l}\text { Hemström, } \\
\text { Mahapatra e } \\
\text { Gustavsson } \\
\text { (2011) }\end{array}$ & $\begin{array}{l}\text { Identificar a percepção de } \\
\text { arquitetos com relação à } \\
\text { utilização do LWF na } \\
\text { construção de prédios na Suécia }\end{array}$ & $\begin{array}{l}\text { Uso de questionário } \\
\text { Qualitativo e quantitativo }\end{array}$ & $\begin{array}{l}\text { Especialistas na área } \\
\text { de construção civil, } \\
\text { mais em específico } \\
\text { arquitetos }\end{array}$ \\
\hline $\begin{array}{l}\text { Qu et al. } \\
\text { (2012) }\end{array}$ & $\begin{array}{l}\text { Buscou compreender melhor as } \\
\text { percepções de especialistas } \\
\text { chineses com relação à difusão } \\
\text { do LWF em casas }\end{array}$ & $\begin{array}{l}\text { Uso de questionário } \\
\text { Qualitativo e quantitativo }\end{array}$ & $\begin{array}{l}\text { Especialistas } \\
\text { construção civil e } \\
\text { florestal }\end{array}$ \\
\hline $\begin{array}{l}\text { Mahapatra, } \\
\text { Gustavsson e } \\
\text { Hemström } \\
\text { (2012) }\end{array}$ & $\begin{array}{l}\text { Analisar a influência de } \\
\text { regulamentos, percepções e } \\
\text { emergência ambientais com } \\
\text { relação ao uso e prédios em } \\
\text { LWF na Alemanha, Suécia e } \\
\text { Reino Unido }\end{array}$ & $\begin{array}{l}\text { Análise qualitativa da } \\
\text { informação coletadas } \\
\text { principalmente de fontes } \\
\text { secundárias }\end{array}$ & \\
\hline $\begin{array}{l}\text { Honsson e } \\
\text { Nord (2015) }\end{array}$ & $\begin{array}{l}\text { Explorar o potencial do } \\
\text { mercado prédios em LWF na } \\
\text { Europa }\end{array}$ & $\begin{array}{l}\text { Estudo prospectivo- análise } \\
\text { de cenários Top-down e } \\
\text { análise de difusão da } \\
\text { inovação (Qualitativo) }\end{array}$ & \\
\hline
\end{tabular}


Quadro 8 - Pontos fortes identificados na literatura com relação à difusão do LWF

\begin{tabular}{|c|c|c|c|c|c|}
\hline Variáveis & $\begin{array}{l}\text { Pesquisa } \\
\text { atual }\end{array}$ & $\begin{array}{l}\text { Hemström, } \\
\text { Mahapatra e } \\
\text { Gustavsson } \\
\text { (2011) } \\
\end{array}$ & $\begin{array}{c}\text { Qu et } \\
\text { al. } \\
(2012)\end{array}$ & $\begin{array}{c}\text { Mahapatra, } \\
\text { Gustavsson } \\
\text { e Hemström } \\
(2012)\end{array}$ & $\begin{array}{l}\text { Humerkoski, } \\
\text { Jonsson e } \\
\text { Nord (2015) }\end{array}$ \\
\hline $\begin{array}{l}\text { Madeira material de tradição } \\
\text { para construção }\end{array}$ & & & $X$ & & $\mathrm{X}$ \\
\hline $\begin{array}{l}\text { Grandes área de plantações } \\
\text { florestais }\end{array}$ & $X$ & & $X$ & & \\
\hline $\begin{array}{l}\text { Disponibilidade de importação } \\
\text { de madeira de países } \\
\text { estrangeiros }\end{array}$ & & & $X$ & & \\
\hline $\begin{array}{l}\text { O uso polivalente de recursos } \\
\text { madeireiros é incentivado }\end{array}$ & & & $X$ & & \\
\hline $\begin{array}{l}\text { Incetivos no ensino na área de } \\
\text { construção em madeira pelas } \\
\text { universidades e instituições }\end{array}$ & & & $X$ & & \\
\hline $\begin{array}{l}\text { Incentivo ao ensino na área de } \\
\text { construção em madeira (prédios) } \\
\text { do governo, do setor florestal e } \\
\text { do setor de construção civil }\end{array}$ & & $X$ & & & \\
\hline $\begin{array}{l}\text { Aumento da investigação, } \\
\text { exploração e utilização de áeas } \\
\text { de madeira doméstica }\end{array}$ & & & $X$ & & \\
\hline $\begin{array}{l}\text { Divulgação e incentivo de } \\
\text { instituições estrangeiras para uso } \\
\text { do sistema construtivo no país }\end{array}$ & $X$ & & $X$ & & \\
\hline $\begin{array}{l}\text { Incentivo do governo para } \\
\text { utilização de recursos naturais } \\
\text { renováveis /vantagem ambiental } \\
\text { do sistema construtivo/vantagem } \\
\text { produtiva (flexibilidade, rapidez, } \\
\text { redução de resíduos...) }\end{array}$ & $X$ & $X$ & $X$ & $X$ & $X$ \\
\hline $\begin{array}{l}\text { Sistema construtivo apresenta } \\
\text { futuro promissor para } \\
\text { desenvolvimento no longo prazo } \\
\text { /bons resultados identificados } \\
\text { até o momento com relação a } \\
\text { sua aplicação e utilização, tais } \\
\text { como manutenção fácil, rapidez } \\
\text { do processo, etc. }\end{array}$ & & & $\mathrm{X}$ & $X$ & $X$ \\
\hline
\end{tabular}


Quadro 9 - Pontos fracos identificados na literatura com relação à difusão do LWF

\begin{tabular}{|c|c|c|c|c|c|}
\hline Variáveis & $\begin{array}{c}\text { Pesquisa } \\
\text { atual }\end{array}$ & $\begin{array}{l}\text { Hemström, } \\
\text { Mahapatra e } \\
\text { Gustavsson } \\
(2011) \\
\end{array}$ & $\begin{array}{c}\text { Qu et al. } \\
\text { (2012) }\end{array}$ & $\begin{array}{c}\text { Mahapatra, } \\
\text { Gustavsson } \\
\text { e Hemström } \\
(2012) \\
\end{array}$ & $\begin{array}{l}\text { Humerkoski, } \\
\text { Jonsson e } \\
\text { Nord (2015) }\end{array}$ \\
\hline $\begin{array}{l}\text { Falta de políticas governamentais/ } \\
\text { conscientização }\end{array}$ & $X$ & & $X$ & & \\
\hline $\begin{array}{l}\text { Falta de profissionais } \\
\text { qualificados/conscientização de } \\
\text { profissionais }\end{array}$ & $X$ & $X$ & $X$ & & $X$ \\
\hline $\begin{array}{l}\text { Falta de pesquisa na } \\
\text { área/divulgação e uso do sistema } \\
\text { construtivo, principalmente da } \\
\text { madeira }\end{array}$ & $X$ & & $X$ & & \\
\hline $\begin{array}{l}\text { Falta de madeira específica para } \\
\text { construção / madeira de qualidade, } \\
\text { plantada especificamente para } \\
\text { construção de edificações }\end{array}$ & $X$ & & $X$ & & \\
\hline $\begin{array}{l}\text { Falta de tecnologia avançada na } \\
\text { área }\end{array}$ & & & X & & \\
\hline $\begin{array}{l}\text { Falta de interesse do setor da } \\
\text { construção civil em investir na área, } \\
\text { de investimentos para atender a } \\
\text { esse sistema estrutura/integração do } \\
\text { setor } \\
\text { Os agentes da cadeia de } \\
\text { suprimentos de modo geral não } \\
\text { estão preparados para atender a } \\
\text { esse sistema construtivo }\end{array}$ & $X$ & $X$ & & $X$ & $X$ \\
\hline $\begin{array}{l}\text { Preconceito dos agentes da cadeia } \\
\text { de suprimentos com relação às } \\
\text { características da madeira para } \\
\text { edificações - engenheiros, } \\
\text { empreiteiros e arquitetos } \\
\text { (resistência, estabilidade, } \\
\text { durabilidade e vida útil da } \\
\text { madeira), o que dificulta a } \\
\text { competição com outras técnicas } \\
\text { construtivas }\end{array}$ & $X$ & $X$ & & $X$ & $\mathrm{X}$ \\
\hline $\begin{array}{l}\text { Tradição do uso do concreto para } \\
\text { construção civil em edifícios em } \\
\text { geral (Brasil) e em prédios (nos } \\
\text { outros estudos) }\end{array}$ & $X$ & $X$ & & & $X$ \\
\hline $\begin{array}{l}\text { Seguro mais caro para edificações } \\
\text { em madeira }\end{array}$ & $\mathrm{X}$ & & & $\mathrm{X}$ & \\
\hline $\begin{array}{l}\text { Não aceitação da madeira no } \\
\text { ambiente construído por parte dos } \\
\text { usuários }\end{array}$ & $X$ & & & $X$ & \\
\hline $\begin{array}{l}\text { Falta de desenvolvimento de } \\
\text { normas para os produtos de } \\
\text { construção em madeira, importante } \\
\text { para assegurar a expansão } \\
\text { substancial das construções de } \\
\text { madeira }\end{array}$ & $X$ & & & $X$ & $X$ \\
\hline $\begin{array}{l}\text { Variação das necessidades técnicas } \\
\text { para construção conforme as } \\
\text { diferentes regiões/falta de padrão }\end{array}$ & $X$ & & X & & $X$ \\
\hline $\begin{array}{l}\text { Custos mais elevados de } \\
\text { manutenção das fachadas }\end{array}$ & & & & & X \\
\hline
\end{tabular}


Quadro 10 - Estratégias identificadas na literatura com o objetivo de difundir o LWF

\begin{tabular}{|c|c|c|c|c|c|}
\hline Estratégias & $\begin{array}{c}\text { Pesquisa } \\
\text { atual }\end{array}$ & $\begin{array}{l}\text { Hemström, } \\
\text { Mahapatra e } \\
\text { Gustavsson } \\
(2011) \\
\end{array}$ & $\begin{array}{l}\text { Qu et } \\
\text { al. } \\
(2012)\end{array}$ & $\begin{array}{c}\text { Mahapatra, } \\
\text { Gustavsson } \\
\text { e Hemström } \\
(2012) \\
\end{array}$ & $\begin{array}{l}\text { Humerkoski, } \\
\text { Jonsson e } \\
\text { Nord (2015) }\end{array}$ \\
\hline $\begin{array}{l}\text { Regulamentar/Estabelecer normas e } \\
\text { políticas adequadas para o } \\
\text { desenvolvimento do mercado e meio } \\
\text { ambiente }\end{array}$ & $\mathrm{X}$ & $X$ & $\mathrm{X}$ & & \\
\hline $\begin{array}{l}\text { Apresentar mais exemplos do LWF } \\
\text { de forma a incentivar a cadeia de } \\
\text { suprimentos a se mobilizar para isso }\end{array}$ & $\mathrm{X}$ & $X$ & & & \\
\hline $\begin{array}{l}\text { Divulgar/Educar (população e } \\
\text { profissionais de modo geral) mais } \\
\text { sobre as propriedades da madeira. } \\
\text { Apresentar como fonte renovável e } \\
\text { sustentável. } \\
\text { Divulgar a durabilidade da madeira, } \\
\text { sua resistência a terremotos, suas } \\
\text { propriedades acústicas e térmicas, } \\
\text { etc. }\end{array}$ & $\mathrm{X}$ & & $\mathrm{X}$ & X & \\
\hline $\begin{array}{l}\text { Incentivar a plantação } \\
\text { específica/setor madeireiro para uso } \\
\text { da madeira na construção civil e } \\
\text { desenvolvimento da indústria } \\
\text { (plantio, colheita, operação, venda, } \\
\text { etc.), trazendo mais tecnologia, a fim } \\
\text { de melhorar a qualidade e o } \\
\text { processamento da madeira }\end{array}$ & $\mathrm{X}$ & & $\mathrm{X}$ & X & \\
\hline $\begin{array}{l}\text { Mais fomentação da pesquisa na área } \\
\text { com o objetivo de superar os } \\
\text { preconceitos }\end{array}$ & $X$ & & & $X$ & X \\
\hline $\begin{array}{l}\text { Maior colaboração entre a indústria, } \\
\text { o governo, pesquisadores e } \\
\text { especialistas na área para } \\
\text { disseminação e criação de uma rede } \\
\text { mais sólida }\end{array}$ & $\mathrm{X}$ & & & $X$ & $X$ \\
\hline $\begin{array}{l}\text { Implantação de impostos sobre } \\
\text { energia e carbono para internalizar os } \\
\text { custos externos da produção de } \\
\text { materiais de construção com o } \\
\text { objetivo de melhorar a } \\
\text { competitividade econômica da } \\
\text { madeira como material estrutural }\end{array}$ & & & & $X$ & $X$ \\
\hline $\begin{array}{l}\text { Acordos com governo e do setor para } \\
\text { reduzir custos administrativos } \\
\text { (impostos) com o objetivo de } \\
\text { impulsionar o setor }\end{array}$ & $\mathrm{X}$ & & & & \\
\hline
\end{tabular}

De modo geral, as estratégias para difusão do LWF são direcionadas para ações regulamentadoras, que dependem do incentivo do governo e principalmente dos setores da construção civil e madeireiro. Em paralelo a essas ações, a academia possui um papel forte do quesito divulgação do sistema e na capacitação de profissionais para a área.

\section{Considerações finais}

O presente trabalho propõe o uso dos cenários prospectivos com o objetivo de contribuir para disseminação do sistema construtivo light wood frame no Brasil. O enfoque dado nesta pesquisa levou em consideração a análise de três cenários, sob as perspectivas otimista, intermediária e pessimista. Com esta pesquisa foi possível explorar o potencial do futuro do LWF no Brasil. No 
primeiro momento foram identificadas as variáveis críticas que influenciam de forma direta sua expansão e, em seguida, foi realizada uma discussão de cunho mais exploratório com os especialistas, que puderam apresentar seu ponto de vista e estratégias para cada cenário elaborado. A atividade prospectiva proposta neste trabalho permite fomentar o pensamento crítico sobre o mercado, o setor e a tecnologia, conduzido a uma reflexão sobre as possibilidades de mudanças estruturais no ambiente operacional.

Os resultados da pesquisa mostram que a expansão do LWF no Brasil depende fortemente dos incentivos governamentais, do aumento da integração dos agentes tanto da cadeia de valor da construção civil como do setor madeireiro, da necessidade de disseminar mais informações aos usuários finais como forma de combate ao preconceito com o uso da madeira e, por fim, da necessidade de formar profissionais capacitados para atuar de forma direta com a construção em madeira. O que se percebe de fato é que as principais barreiras de difusão do LWF estão relacionadas com a credibilidade do sistema em toda a cadeia de suprimentos do setor, não somente do setor da construção civil, mas também do setor madeireiro e dos próprios usuários.

A estrutura escolhida permitiu tirar conclusões gerais sobre o potencial de mercado do LWF no Brasil. Como o sistema LWF ainda é uma tecnologia em expansão, acredita-se ser importante o desenvolvimento de pesquisa de caráter reflexivo. Nesse sentido, o estudo exploratório buscou, por meio da investigação e análise de um grupo específico, gerar uma discussão sobre as variáveis críticas que influenciam o LWF no Brasil e sobre estratégias que possam ser relevantes para sua disseminação. Esses resultados são um ponto de partida válido para uma discussão mais aprofundada sobre o desenvolvimento do sistema em todo o país.

\section{Referências}

ARAÚJO, V. de et al. Woodframe: light framing houses for developing countries. Revista de la Construcción, v. 15, n. 2, p. 78-87, 2016.

BRASIL. DATec No020-A. Sistema de vedação vertical leve em madeira. Instituto Falcão Bauer de Qualidade de São Paulo. São Paulo, 2015.

Disponível em: <http://www.tecverde.com.br/wpcontent/uploads/2016/07/datec-20A.pdf $>$. Acesso em: 2 set. 2017.
CARDOSO, L. A. Estudo do Método Construtivo Wood Framing Para Construção de Habitações de Interesse Social. Santa Maria, 2015. 79 f. Monografia (Trabalho de Conclusão do Curso de Engenharia Civil) - Escola de

Engenharia, Universidade Federal de Santa Maria, Santa Maria, 2015.

\section{CATTANI, A. D. Trabalho e Tecnologia:} dicionário crítico. Petrópolis: Vozes, 1997.

CONSTRUÇÃO civil impulsiona indústria da madeira; Moradias. Revista da Madeira, v. 126, fev. 2011. Disponível em:

<http://www.remade.com.br/>. Acesso em: 20 out. 2017.

ESPÍNDOLA, L. da R. Simulação de Eficiência Energética em Projeto Para Habitação Social em Madeira. In: ENCONTRO BRASILEIRO EM MADEIRAS E EM ESTRUTURAS DE MADEIRA. 10., Curitiba, 2016. Anais... Curitiba: EBRAMEM, 2016.

FEDERAÇÃO DAS INDÚSTRIAS DO ESTADO DO PARANÁ. Comissão Casa Inteligente. Conselhos temáticos e setoriais. Base florestal. Comissão Casa Inteligente. Disponível em: $<$ http://www.fiepr.org.br/paraempresas/conselhos/base_florestal/comissao-casainteligente-1-1135-87186.shtml>. Acesso em: 10 out. 2017.

\section{FERREIRA, A. S. Estudo Comparativo de} Sistemas Construtivos Industrializados: paredes de concreto, steel frame e wood frame. Santa Maria, 2014. 62 f. Dissertação (Trabalho de Conclusão do Curso de Engenharia Civil) - Escola de Engenharia, Universidade Federal de Santa Maria, Santa Maria, 2014.

FINATTI, E. M. Wood Frame: sistema construtivo em madeira. In: SIMPÓSIO DE MADEIRA, 2.; CONSTRUÇÃO - CONSTRUÇÕES

SUSTENTÁVEIS USANDO MADEIRA DE FLORESTA PLANTADA, 38., Curitiba, 2014. Anais... Curitiba, 2014.

GODET, M. Introduction to la Prospective: seven key ideas and one scenario method. Futures, Amsterdam, p. 134-157, 1986.

GOLD, S.; RUBIK, F. Consumer Attitudes Towards Timber as a Construction Material and Towards Timber Frame Houses: selected findings of a representative survey among the German population. Journal of Cleaner Production, v. 17, n. 2, p. 303-309, 2009. 
GOMES, J. O.; LACERDA, J. F. S. B. Uma Visão Mais Sustentável dos Sistemas Construtivos no Brasil: análise do estado da arte. E-Tech: Tecnologias para Competitividade Industrial, Florianópolis, v. 7, n. 2, 2014.

HEMSTRÖM, K.; MAHAPATRA, K.; GUSTAVSSON, L. Perceptions, Attitudes and Interest of Swedish Architects Towards the Use of Wood Frames in Multi-Storey Buildings.

Resources, Conservation and Recycling, p. 1013-1021, 2011.

HUMERKOSKI, E.; JONSSON, R.; NORD, T. Context, Drivers, and Future Potential For WoodFrame Multi-Story Construction in Europe.

Technological Forecasting \& Social Change, p. 181-196, 2015.

JADID, M.; BADRAH, M. Decision Support System Approach For Construction Materials Selection. In: SYMPOSIUM ON SIMULATION FOR ARCHITECTURE AND URBAN DESIGN, Orlando, 2012. Proceedings... Orlando, 2012.

KOKUBUN, Y. E. O Processo de Produção de Um Sistema Construtivo em Painéis Estruturais Pré-Fabricados em Madeira. São Paulo, 2014. 171 f. Dissertação (Mestrado em Arquitetura e Urbanismo) - Faculdade de Arquitetura e Urbanismo, Universidade de São Paulo, São Paulo, 2014.

LEITE, J. C. P. S.; LAHR, F. A. R. Diretrizes Básicas Para Projeto em Wood Frame. Revista Construindo, v. 7, n. 2, jul./dez. 2015.

LIGNUM: bosque madera and tecnologia. Construcción en madera: la opción eficiente, Santiago, v. 23, n. 143, p. 76-76, 2013.

MAHAPATRA, K. Diffusion of Innovative Domestic Heating Systems and Multi-Storey Wood-Framed Buildings in Sweden. PhD Thesis 33, Mid Sweden University, Ostersund, 2007.

MAHAPATRA, K.; GUSTAVSSON, L.; HEMSTRÖM, K. Multi-Storey Wood-Frame Buildings in Germany, Sweden and the UK. Constructon Innovation, v. 12, n. 1, p. 62-85, 2012.

MOLINA, J. C.; CALIL, C. J. Sistema Construtivo em Wood Frame Para Casas De Madeira. Semina: Ciências Exatas e Tecnológicas, Londrina, v. 31, n. 2, p. 143- 156, 2010.
NASCIMENTO, O. L. Alvenarias. 2. ed. Rio de Janeiro: IBS; CBCA, 2004. (Série Manual de Construção em Aço).

OLIVEIRA, L. A. Avaliação da Aceitabilidade do Sistema Construtivo "Wood Frame”. Curitiba, 2014. 61 f. Monografia (Especialização em Construções Sustentáveis) - Universidade Federal Tecnológica do Paraná, Curitiba, 2014.

PEREIRA, N. N.; VIEIRA, R. B. "Wood Frame”: Tecnologia de Construção Sustentável. Revista Perquirere, v. 12, n. 1, p. 194-213, jul. 2015.

PROGRAMA BRASILEIRO DE QUALIDADE E PRODUTIVIDADE. Projetos: Sistema Nacional de Avaliações Técnicas- SINAT. PBQP-H; Ministério das Cidades, 2016. Disponível em: <http://pbqp-h.cidades.gov.br/>. Acesso em: 20 abr. 2017.

QU, M. et al. Experts’ Assessment of the Development of Wood Framed Houses in China. Journal of Cleaner Production, v. 31, p. 100105, 2012.

SILVA, R. G. da L. Viabilidade Técnica do Sistema Construtivo Light Wood Frame na Constraução de Uma Unidade Habitacional de Dois Pavimentos: estudo de caso no município de Arcos - MG. Formiga, 2015. 69 f. Monografia (Curso de Graduação em Engenharia Civil) Unifor, Formiga, 2015.

SOUZA, L. G. Análise Comparativa do Custo de Uma Casa Unifamiliar nos Sistemas Construtivos de Alvenaria, Madeira de Lei e Wood Frame.

Revista Especialize online, Florianópolis, 2013.

TEREZO, R. F. Tecnologia e Qualidade Para Produtos em Pinus Voltadas ao Mercado da Construção Civil. In: CONGRESSO INTERNACIONAL DO PINUS, 17., Lages, 2011. Anais... Lages, 2011.

THALLON, R. Graphic Guide to Frame Construction. Newtown: Taunton, 2008.

WANG, L.; TOPPINEN, A.; JUSLIN, H. Use of Wood in Green Building: a study of expert perspectives from the UK. Journal of Cleaner Production, v. 65, p. 350-361, 2014. 


\section{Nicolle Christine Sotsek}

Programa de Pós-Graduação em Engenharia de Construção Civil, Centro Politécnico | Universidade Federal do Paraná | J ardim das Américas | Caixa Postal 19.011 | CEP 81531-980 | Curitiba - PR - Brasil | Tel.:(41) 3361-3110| E-mail: nicollesotsek@yahoo.com.br

\section{Adriane de Paula Lacerda Santos}

Programa de Pós-Graduação em Engenharia de Construção Civil, Centro Politécnico | Universidade Federal do Paraná | E-mail: adrianapls1@gmail.com

\section{Revista Ambiente Construído}

Associação Nacional de Tecnologia do Ambiente Construído

$$
\begin{aligned}
& \text { Av. Osvaldo Aranha, } 99 \text { - 3o andar, Centro } \\
& \text { Porto Alegre - RS - Brasil } \\
& \text { CEP 90035-190 } \\
& \text { Telefone: }+55 \text { (51) 3308-4084 } \\
& \text { Fax: }+55 \text { (51) 3308-4054 } \\
& \text { www. seer. ufrgs. br/ ambienteconstruido } \\
& \text { E-mail: ambienteconstruido@ufrgs.br }
\end{aligned}
$$

